\title{
Evaluations of an ocean bottom electro-magnetometer and preliminary results offshore NE Taiwan
}

\author{
Ching-Ren Lin ${ }^{1}$, Chih-Wen Chiang ${ }^{2}$, Kuei-Yi Huang ${ }^{2}$, Yu-Hung Hsiao ${ }^{3}$, Po-Chi Chen ${ }^{3}$, Hsu-Kuang Chang ${ }^{3}$, \\ Jia-Pu Jang ${ }^{3,5}$, Kun-Hui Chang ${ }^{1}$, Feng-Sheng Lin ${ }^{1}$, Saulwood Lin ${ }^{4}$, and Ban-Yuan Kuo ${ }^{1}$ \\ ${ }^{1}$ Institute of Earth Sciences, Academia Sinica, Taipei 11529, Taiwan \\ ${ }^{2}$ Institute of Earth Sciences, National Taiwan Ocean University, Keelung 20224, Taiwan \\ ${ }^{3}$ Taiwan Ocean Research Institute, National Applied Research Laboratories, Kaohsiung 80143, Taiwan \\ ${ }^{4}$ Institute of Oceanography, National Taiwan University, Taipei 10617, Taiwan \\ ${ }^{5}$ Department of Electrical Engineering, National Kaohsiung University of Science and Technology, Kaohsiung 80778, Taiwan
}

Correspondence: Chih-Wen Chiang (zjiang@ntou.edu.tw)

Received: 11 April 2019 - Discussion started: 8 May 2019

Revised: 19 August 2019 - Accepted: 19 August 2019 - Published: 24 September 2019

\begin{abstract}
The first stage of field experiments involving the design and construction of a low-power consumption ocean bottom electro-magnetometer (OBEM) has been completed, which can be deployed for more than $180 \mathrm{~d}$ on the seafloor with a time drift of less than $0.95 \mathrm{ppm}$. To improve the performance of the OBEM, we rigorously evaluated each of its units, e.g., the data loggers, acoustic parts, internal wirings, and magnetic and electric sensors, to eliminate unwanted events such as unrecovered or incomplete data. The first offshore deployment of the OBEM together with ocean bottom seismographs (OBSs) was performed in NE Taiwan, where the water depth is approximately $1400 \mathrm{~m}$. The total intensity of the magnetic field (TMF) measured by the OBEM varied in the range of $44100-44150 \mathrm{nT}$, which corresponded to the proton magnetometer measurements. The daily variations in the magnetic field were recorded using the two horizontal components of the OBEM magnetic sensor. We found that the inclinations and magnetic data of the OBEM varied with two observed earthquakes when compared to the OBS data. The potential fields of the OBEM were slightly, but not obviously, affected by the earthquakes.
\end{abstract}

\section{Introduction}

Marine electromagnetic exploration is a geophysical prospecting technique used to reveal the electrical resistivity features of the oceanic upper mantle down to depths of sev- eral hundreds of kilometers in different geologic and tectonic environments, such as in areas around mid-oceanic ridges, areas around hot-spot volcanoes, subduction zones, and normal ocean areas between mid-oceanic ridges and subduction zones (Ellis et al., 2008; Evans et al., 2005; Key, 2012; Utada, 2015).

Even though many magnetotelluric explorations have investigated deep electrical structures on Taiwan (Bertrand et al., 2009, 2012; Chiang et al., 2011, 2010, 2015, 2008), there were no marine electromagnetic experiments around Taiwan until 2010. The first generation of ocean bottom seismographs (OBSs) was developed by the Institute of Earth Sciences, Academia Sinica (IES), Taiwan Ocean Institute, National Applied Research Laboratories, and the Institute of Undersea Technology, National Sun Yat-sen University (OBS R\&D team), in 2009, called Yardbird-20s. These OBSs have acquired large amounts of data via a series of deployments offshore Taiwan that can be used to study plate tectonics and crustal characteristics (Kuo et al., 2015, 2012, 2014). Subsequently, the OBS R\&D team developed an ocean bottom electro-magnetometer (OBEM) modified from the OBS based on important developmental experiments.

The novel OBEM was constructed by the OBS R\&D team and has completed the first stage of field experiments by the Institute of Earth Sciences, National Ocean Taiwan University, and IES. One OBEM and six broadband OBSs, called Yardbird-BBs (Broadband Yardbirds), were deployed at the western end of the Okinawa Trough (OT), NE Taiwan, for 
Table 1. Specifications of the OBEM compared to the Japanese OBEM and OBE (Kasaya and Goto, 2009).

\begin{tabular}{llll}
\hline & Taiwan (OBEM) & Japan (OBEM) & Japan (OBE) \\
\hline Sampling rate $(\mathrm{Hz})$ & 10 & 8 & 1 \\
AD converter (bits) & 24 & 16 & 24 \\
Resolution $(\mu \mathrm{V} / \mathrm{LSB})$ & 1.5245 & 0.305176 & 0.0019 \\
Resolution of magnetic field (nT/LSB) & 0.010671 & 0.01 & none \\
Max battery lifetime & About $180 \mathrm{~d}$ & About $40 \mathrm{~d}$ & About $30 \mathrm{~d}$ \\
Power supply & Lithium battery & Lithium battery & Li-ion rechargeable battery \\
Max memory/media & 64 GB/SD card & 2 GB/CF card & 1 GB/CF card \\
Communication port & USB 2.0 & USB 1.1/RS-232C & RS-232C \\
Clock drift & $<0.95 \mathrm{ppm}$ & $<2 \mathrm{ppm}$ & $<2 \mathrm{ppm}$ \\
\hline
\end{tabular}

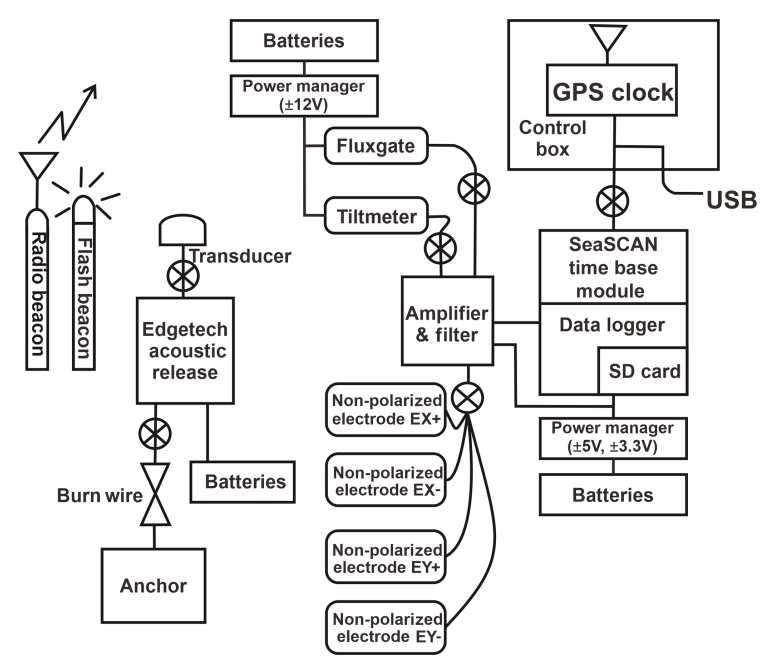

Figure 1. A block diagram of the OBEM. The inputs of the two electric fields, two inclinations and three magnetic fields pass through the Amp \& LPF in the data logger, which contains a 64 GB SD card. The SeaSCAN time base module is integrated into the data logger and has a timing error smaller than $3 \mathrm{~s} \mathrm{yr}^{-1}$. The EdgeTech acoustic transceiver and transducer are used for the positioning and releasing of the anchor. The radio and flash beacons are used to locate the OBEM at the sea surface during recovery operations.

field testing in March 2018. The water depth in this area is approximately $1400 \mathrm{~m}$. All the instruments were successfully recovered in May 2018 after collecting the first OBEM field data in Taiwan. Here, we introduce the OBEM design, specifications, calibration procedures, and its further developments and improvements.

\section{The OBEM design}

The OBEM is designed to be wireless deep underwater equipment; however, the power supply is limited for the wireless OBEM because the batteries cannot be directly charged via electric cables from vessels. Therefore, designing lowpower consumption for the OBEM and high-efficiency battery packs is critically required for long periods of opera- tion. The major units of the OBEM include a data logger, a magnetic sensor, a tiltmeter, electric receivers with an armfolding mechanism, a relocation system, recovery units and an anchor. All the units for the OBEM use nonmagnetic materials (e.g., the screws and anchor). Figure 1 shows a block diagram of the OBEM, whereas the specifications of the OBEM compared to the Japanese system (Kasaya and Goto, 2009) are shown in Table 1. We designed the data logger, release mechanism and the OBEM platform to integrate all the sensors or units purchased from related manufacturers and focused on the issues of saving power and reducing costs. The detailed requirements of the OBEM are listed below.

1. A magnetic sensor with three axes for measuring magnetic fields.

2. A tiltmeter with two axes for measuring leveling changes to correct the tilt error of the magnetic sensor.

3. Two pairs of non-polarized electrodes with $2 \mathrm{~m}$ bendable arms with a total distance between the electrodes of approximately $4.5 \mathrm{~m}$.

4. A highly accurate data logger with at least seven channels and a sampling rate of greater than or equal to 10 samples per second (SPS).

5. Operation time of more than $180 \mathrm{~d}$.

6. An internal timing error of less than $3 \mathrm{~s} \mathrm{yr}^{-1}$ synchronized with GPS.

7. Acoustic relocation and recovery control systems.

8. Power consumption of less than $1.5 \mathrm{~W}$.

9. A radio beacon, flush beacon, reflect label and orange flag for identification on the sea surface during instrument recovery.

10. A $0.75 \mathrm{~m} \mathrm{~s}^{-1}$ subside rate for deployment and float-up rate for recovery.

11. A maximum deployment depth of more than $6000 \mathrm{~m}$ appropriate for most seawater depths offshore Taiwan. 
The solutions found for the OBEMs are listed below.

1. A fluxgate with three axes with a sensitivity of $\pm 70000 \mathrm{nT}$ and a noise level $<6 \mathrm{pTrms} / \sqrt{ } \mathrm{Hz}$ at $1 \mathrm{~Hz}$ adding a buffer amplifier with gain $=0.2$ and passive low-pass filter at $50 \mathrm{~Hz}$; the scaling temperature coefficient is $\pm 15 \mathrm{ppm}^{\circ} \mathrm{C}^{-1}$, whereas the offset temperature coefficient is $\pm 0.1 \mathrm{nT}^{\circ} \mathrm{C}^{-1}$.

2. Four non-polarized electrodes $(\mathrm{Ag} / \mathrm{AgCl})$, with a selfnoise level $<625 \mu \mathrm{V}$ adding a buffer amplifier with gain $=20$ and two active low-pass filters at $50 \mathrm{~Hz}$.

3. A tiltmeter with two axes with inclinations of $\pm 30^{\circ}$ adding a buffer amplifier gain $=0.2$ and a passive lowpass filter at $50 \mathrm{~Hz}$.

4. Two pairs of silver chloride electrodes with a $2 \mathrm{~m}$ armfolding mechanism.

5. A low-noise and low-power consumption eightdifferential channel 24 bit A/D data logger with an accurate internal timing clock.

6. Acoustic transponder and controller units.

7. Radio beacon and flash beacon units.

8. An OBEM platform modified from that of OBS.

9. High-efficiency lithium battery packs for the sensors and data logger.

\section{Units of the OBEM and their specifications}

The OBEM is recovered by releasing its anchor from the seafloor via an onboard acoustic command. The OBEM is returned to the sea surface via buoyancy when the anchor is released. There are two typical release mechanisms available for OBEMs to unlock their anchors: spin motor and burnwire systems (Kasaya and Goto, 2009). The OBEM uses the burn-wire system because it weighs less than the spin motor system. The acoustic controller and transducer use ORE \#B980175 ASSY PCB and \#D980709, respectively, manufactured by EdgeTech, USA, for the corresponding functions of OBEM recovery and underwater ranging. The ASSY PCB acoustic controller uses a binary FSK (frequency-shift keying) encoder, including the commands "RELEASE1", "RELEASE2", "DISABLE", "ENABLE" and "OPTIONAL1". The frequency of the acoustic range ranges from 7.5 to $15 \mathrm{kHz}$ in increments of $0.5 \mathrm{kHz}$ with a sensitivity of $80 \mathrm{~dB}$ re $1 \mathrm{~V} \mathrm{muPa}^{-1}$. The \#D980709 transducer can work at a depth of $6000 \mathrm{~m}$ and in environments from -10 to $+40^{\circ} \mathrm{C}$.

The EdgeTech $8011 \mathrm{M}$ model acoustic commander $(8011 \mathrm{M})$ is used on board to send the ENABLE command to open the ranging function, the "RANGE" command to measure the distance between the OBEM and the research vessel,

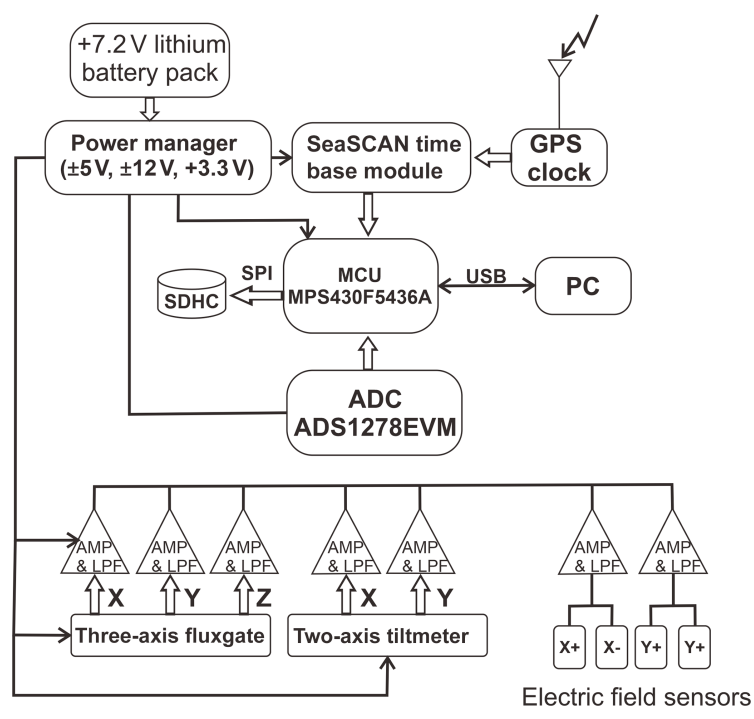

Figure 2. A block diagram of the OBEM data logger. The ADS1278EVM is a 24 bit A/D with eight inputs used for converting analog signals via the amplifier and low-pass filter (Amp \& LPF) to digital data. The Amp \& LPF adjusts the output voltages of the sensors of the fluxgate, tiltmeter and electric receivers to suitable A/D input levels. The two MCUs of the MPS430F5436A process the timing synchronization by the SeaSCAN of time base and GPS modules, the digital data storage to the SD card with a standard $\mathrm{SDHC}$, and the user interface communication with a PC.

the DISABLE command to close the ranging function, and the RELEASE1 command to activate the burn-wire system to release the anchor. The RELEASE1 command persists for 15 min unless terminated by the OPTIONAL1 command.

We selected the RF-700A and ST-400A NOVATECH models for the radio and flash beacons, respectively, for use in the OBEM. The maximum deployment depth for these models is $7300 \mathrm{~m}$. The radio beacon is turned ON by sending a VHF (very high-frequency) signal, and the flush beacon is turned $\mathrm{ON}$ at atmospheric pressure of less than $1 \mathrm{~atm}$ (equal to a depth of $10 \mathrm{~m}$ below the sea surface) in a dark environment. The beacons are also turned OFF at a depth of $10 \mathrm{~m}$ or at atmospheric pressure of less than $1 \mathrm{~atm}$, respectively. These two beacons have four independently installed C-type alkaline batteries that allow for $6 \mathrm{~d}$ of continuous operation at a maximum; this power supply differs from that of the data logger. The two independent power supply layouts allow the beacons to properly operate even if the power supply for the data logger fails. An onboard radio scanner detects the signal transmitted from the radio beacon at a distance of 6.4 $12.9 \mathrm{~km}$ when the OBEM is floating on the surface. These two beacons can assist in locating the OBEM on the sea surface in both daytime and nighttime.

TL-5930 model lithium batteries manufactured by TADIRAN are used for the OBEM, with specifications of $3.6 \mathrm{~V}$, $19 \mathrm{Ah}$ and a D type, with characteristics of high energy density and a low self-discharge rate suitable for long periods of 
operation. Figure 2 shows a block diagram of the OBEM data logger. The ADC1278EVM model is a 24 bit A/D converter used for the inputs of the three fluxgate axes, the two tiltmeter axes and two pairs of non-polarized electrodes with a sampling rate of 10 SPS. An amplifier and a low-pass filter (Amp \& LPF) were designed for the magnetic sensor, leveling sensor and electric receiver inputs. The two MPS430F5436A microcontrollers (MCUs) process the timing synchronization of the time base manufactured by SeaSCAN, USA, and the GPS modules; the digital data are stored on a Secure Digital (SD) memory card with a standard Secure Digital High Capacity (SDHC), and the user interface communicates with a PC. The time base module supplies a precise time base signal to the data logger, whereas the SISMTB Ver 4.1 time base module generates a precise $125 \mathrm{~Hz}$ clock that supports a timing error smaller than $3 \mathrm{~s} \mathrm{yr}^{-1}$. Even though the time base module supports a very small timing error of $3 \mathrm{~s} \mathrm{yr}^{-1}$, the data logger clock is still synchronized with the GPS on deck for timing corrections after recovering the OBEM. The maximal capacity of the SD card is $64 \mathrm{~GB}$ and can support data storage for more than 1 year with a sampling rate of 10 SPS.

Two $17 \mathrm{in.} \mathrm{glass} \mathrm{VITROVEX} \mathrm{spheres} \mathrm{manufactured} \mathrm{by}$ Nautilus Marine Service GmbH, Germany, are used for the OBEM. These glass spheres contain the fluxgate and tiltmeter (sensor ball) and the seven channels of the Amp \& LPF, data logger, \#B980175 ASSY PCB acoustic controller and batteries (instrument ball) and can be deployed at a depth of $6000 \mathrm{~m}$ and support a total buoyancy of $52 \mathrm{~kg}$. The instrument and sensor balls, the silver chloride electrodes, and the burn-wire system are connected via waterproof cables. There is a pressure-vacuum valve outside the glass spheres that allows a pumped vacuum to be preserved at $0.7 \mathrm{~atm}$; self-fusing butyl rubber tape is used to fill the suture zone between the half glass spheres. In addition, two crossed stainless-steel bands are used to improve the waterproofing of the glass spheres and cover the orange PE cases. Four PVC pipes with lengths of $2 \mathrm{~m}$ are combined to form the OBEM platform for the electric receivers, and the silver chloride electrodes are installed at the ends of the pipes. A $60 \mathrm{~kg}$ nonmagnetic anchor is attached to the bottom of the OBEM platform and catches via a releasing mechanism. The anchor can be released using the burn-wire system to recover the OBEM. Figure 3 shows a photograph of the OBEM platform.

\section{Calibrations of the OBEM}

It is necessary to calibrate each unit of the OBEM, including the data logger with the Amp \& LPF, fluxgate, tiltmeter, electrodes, ASSY PCB acoustic controller, transducer and wiring, before and after assembling the OBEM to improve its performance. We describe the series of calibration methods used for the OBEM units in the following section.

Geosci. Instrum. Method. Data Syst., 8, 265-276, 2019

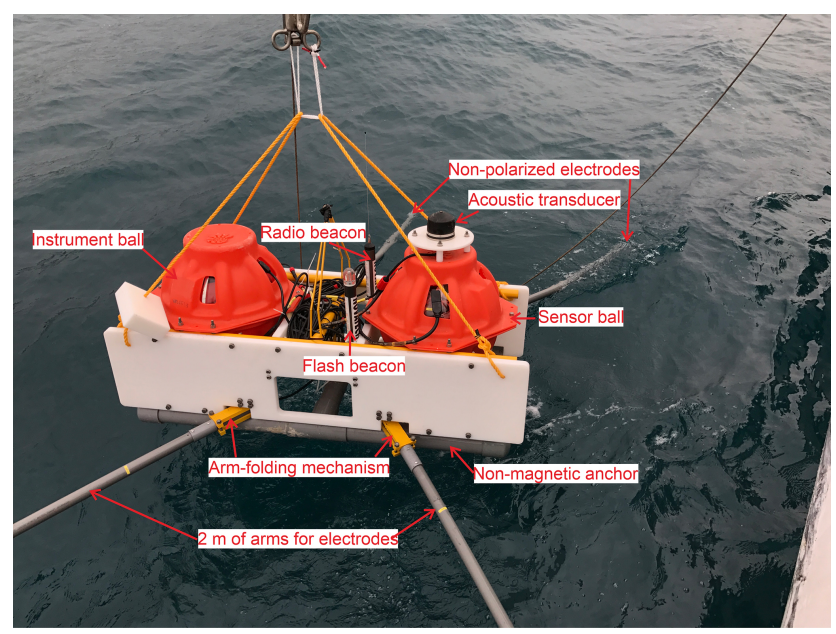

Figure 3. A photograph of the OBEM01 and its specific modules.

\subsection{Calibrations of the background noise of the data logger and the Amp \& LPF}

The background noise of the data logger is defined as

$N_{\mathrm{rms}}=\sqrt{\frac{1}{n}\left(A_{1}^{2}+A_{2}^{2}+\ldots K+A_{n}^{2}\right)}$,

where $n$ is a data point and $A_{1}$ to $A_{n}$ indicate the amplitudes of the data points, 1 to $n$, individually at the short circuit or $0 \mathrm{~V}$. The background noise of the data logger (in "BIT") is calculated as

$\mathrm{d} B_{\mathrm{rms}}=20 \log _{2}\left(N_{\mathrm{rms}}\right)$,

The data logger contains seven input channels called MX, MY, MZ, TX, TY, EX and EY. MX, MY and MZ are used for the magnetic sensor of the fluxgate, TX and TY are used for the tiltmeter, and EX and EY are used for the electric receivers. The calibration procedure is described below.

1. Connect MX, MY, MZ, TX and TY to GND (Ground), $\mathrm{EX}+$ with $\mathrm{EX}$ - and EY+ with EY-.

2. Start the record mode of the data logger, wait for $60 \mathrm{~s}$ to acquire data, and then stop recording data.

3. Download the data from the data logger and convert it to ASCII format. Then, calculate the background noise using Eq. (1) and the background noise in $\mathrm{dB}$ using Eq. (2).

\subsection{Calibrations of the sensitivity, linearity error and dynamic range for the data logger and the Amp \& LPF}

The input ranges of the voltages for MX, MY and MZ are $\pm 10 \mathrm{~V}$, for TX and TY they are $\pm 5 \mathrm{~V}$, and for EX and EY they are $\pm 0.00625 \mathrm{~V}$. The sensitivities are calculated from 
the average count of the input voltages; that is, subtract the average count at zero voltage and then divide by the input voltages:

$S=\operatorname{Average}\left(\frac{\operatorname{Average}\left(C_{\mathrm{i}}\right)-\operatorname{Average}\left(C_{0}\right)}{V_{\mathrm{i}}}\right)$,

where $V_{\mathrm{i}}$ is the input voltage, $C_{\mathrm{i}}$ is the output count saved on the SD card for an input voltage of $V_{\mathrm{i}}$, and $C_{0}$ is the output count saved on the SD card for an input voltage of $0 \mathrm{~V}$. The linearity errors are calculated such that

Error $=\operatorname{Abs}\left[\frac{S_{\mathrm{i}}-S_{\mathrm{T}}}{S_{\mathrm{T}}}\right] 100$,

where $S_{\mathrm{i}}$ is the sensitivity of the input voltage and $S_{\mathrm{T}}$ is the total sensitivity.

The dynamic range is the ratio of the maximum count to the background noise. It is defined as

$D=20 \log \left(\frac{S_{\mathrm{T}} \times V_{\max }}{N_{\mathrm{RMS}}}\right)$,

where $S_{\mathrm{T}}$ is the total sensitivity and $V_{\max }$ is $10 \mathrm{~V}$ for $\mathrm{MX}$, $\mathrm{MY}$ and MZ, $5 \mathrm{~V}$ for TX and TY, and $0.00625 \mathrm{~V}$ for EX and EY. Its calibration procedure is described below.

1. Connect the MX, MY and MZ channels of the data logger to the source voltages generated by the calibrator (FLUKE726) and connect the GND channel of the data logger to the source common point (COM) of FLUKE726.

2. Set the data logger to the recording mode.

3. Set the FLUKE726 output voltages from 0 to $\pm 10 \mathrm{~V}$. Increase and decrease the voltages step by step at $1 \mathrm{~V}$ intervals until $\pm 10 \mathrm{~V}$. The measurement time length for each output voltage is $20 \mathrm{~s}$.

4. Connect the TX and TY channels of the data logger to the source voltages generated by FLUKE726 and connect the GND channel of the data logger to the COM of FLUKE726.

5. Set the FLUKE726 output voltages from 0 to $\pm 5 \mathrm{~V}$. Increase and decrease the voltages step by step at $1 \mathrm{~V}$ intervals until $\pm 5 \mathrm{~V}$. The measurement time length for each output voltage is $20 \mathrm{~s}$.

6. Connect the EX+ and EY+ channels of the data logger to the source voltages generated by FLUKE726, and connect the EX - and EY - channels of the data logger to the COM of FLUKE726.

7. Set the FLUKE726 output voltages from 0 to $\pm 6 \mathrm{mV}$. Increase and decrease the voltages step by step at $1 \mathrm{mV}$ intervals until $\pm 6 \mathrm{mV}$. The measurement time length for each output voltage is $20 \mathrm{~s}$.
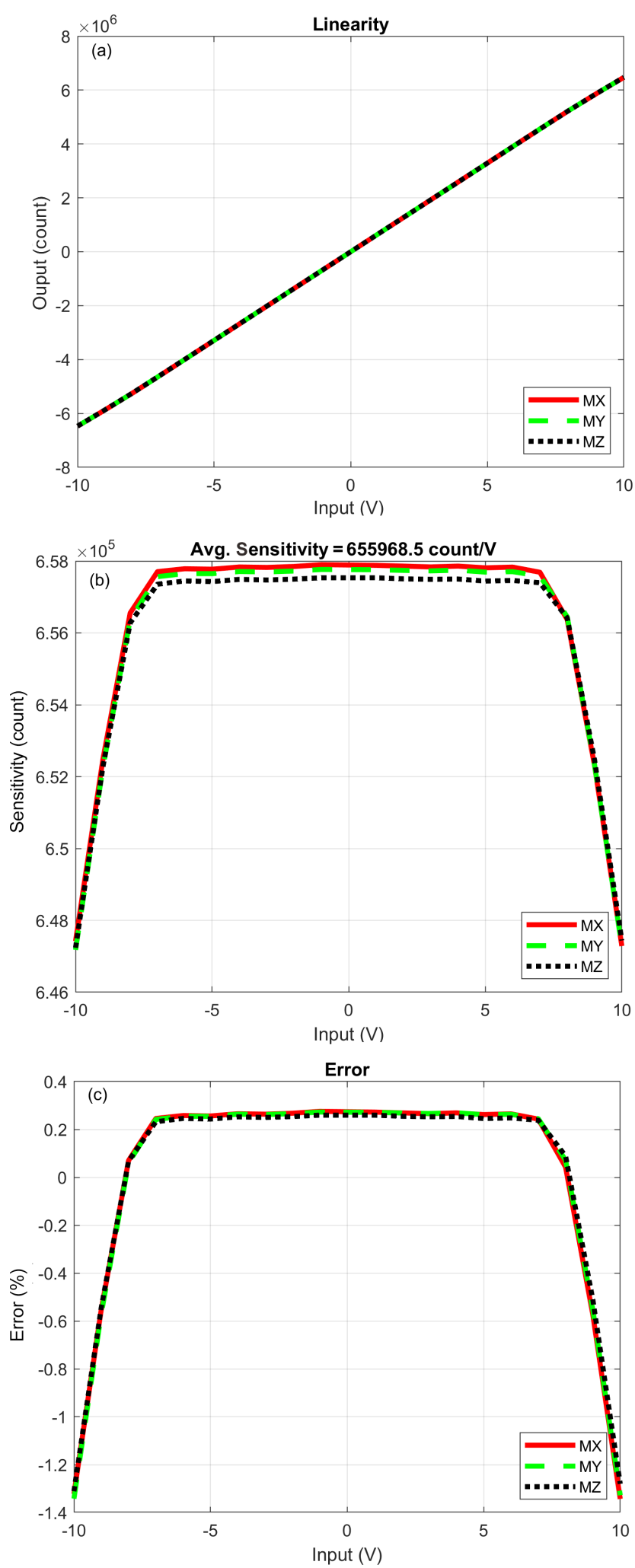

Figure 4. Calibration results for the magnetic channels of the OBEM01. (a) Linearity, (b) sensitivity and (c) error. The average sensitivity is 655968.5 counts $\mathrm{V}^{-1}$, and the maximum error is $<1.35 \%$. 

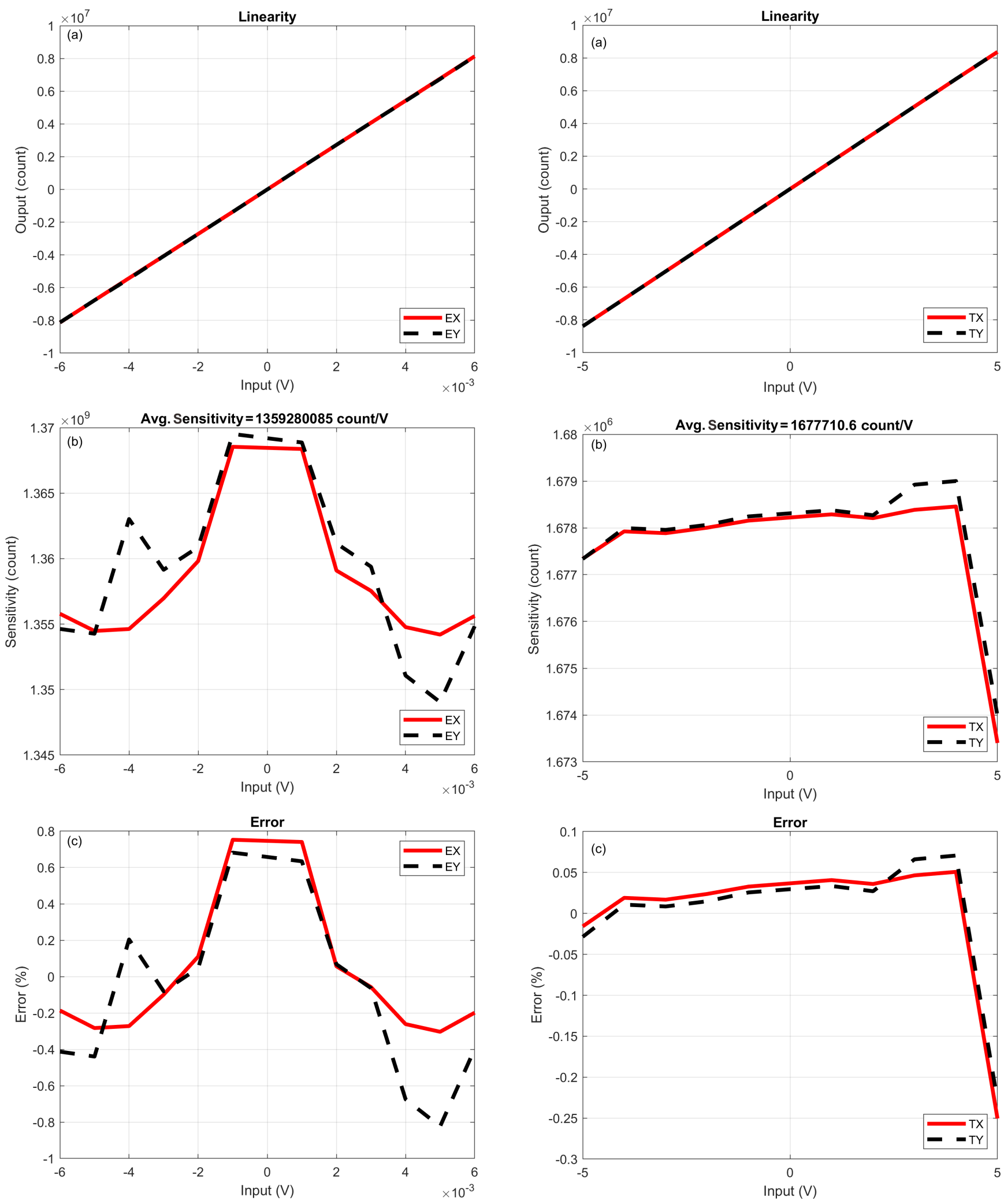

Figure 5. Calibration results for the electric channels of the OBEM01. (a) Linearity, (b) sensitivity and (c) error. The average sensitivity is 1358568047.8 counts $\mathrm{V}^{-1}$, and the maximum error is $<0.8 \%$.

Figure 6. Calibration results for the inclination channels of the OBEM01. (a) Linearity, (b) sensitivity and (c) error. The average sensitivity is 1677710.6 counts $\mathrm{V}^{-1}$, and the maximum error is $<0.25 \%$. 

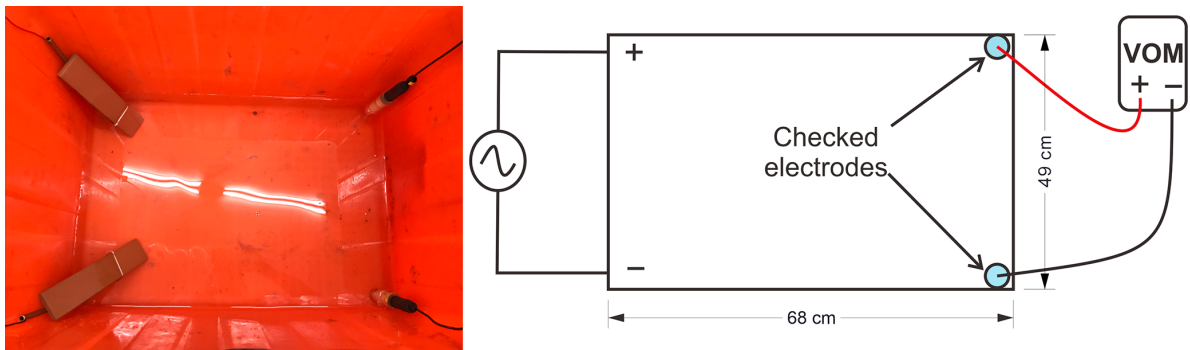

Figure 7. The layout for the evaluation of the electric receivers. Two copper electrodes are used to vary the input signals. A pair of silver chloride electrodes are placed at the corner of a tank with an area of $68 \mathrm{~cm} \times 49 \mathrm{~cm}$ filled with $15 \mathrm{~cm}$ of seawater. A VOM is used to measure the self-potential and impedance of the electrodes.

8. Finally, switch off the recording mode of the data logger, download the data and convert it to ASCII format for analysis. Calculate the sensitivity, linearity error and dynamic range using Eqs. (3), (4) and (5), respectively.

Figure 4 shows a calibration of the magnetic channels (MX, MY and MZ) checking the sensitivity, linearity and error. The average sensitivity is 655968.5 counts $\mathrm{V}^{-1}$ with a maximum error smaller than $1.35 \%$. Figure 5 shows a calibration of the electric channels (EX and EY) checking the sensitivity, linearity and error. The average sensitivity is 135856047.8 counts $\mathrm{V}^{-1}$ with a maximum error smaller than $0.8 \%$. Figure 6 shows a calibration of the tiltmeter channels (TX and TY) checking the sensitivity, linearity and error. The average sensitivity is 1677710.6 counts $V^{-1}$ with a maximum error smaller than $0.25 \%$. The noise level of the data logger is $57.8 \mathrm{~dB}$, whereas its dynamic range is $80.2 \mathrm{~dB}$ at $10 \mathrm{~Hz}$.

\subsection{Evaluation of the current consumption}

The power supplies of the OBEM consist of two 7.2 V battery packs in a series connection with two $3.6 \mathrm{~V}$ lithium batteries. One battery pack is for the data logger and converts to \pm 5 and +3.3 VDC (voltage direct current). The other pack is for the sensors and converts to \pm 5 and +12.0 VDC. Two +7.4 VDC output current batteries were measured for their current consumption measurement using two ammeters connecting the two $+7.4 \mathrm{~V}$ battery packs. Table 2 shows the current consumption of the OBEM system. The maximum current consumptions of the data logger and sensors are 32 and $105 \mathrm{~mA}$, respectively. The total power consumption is less than $1 \mathrm{~W}$, which corresponds to expectations.

\subsection{Evaluation of the electrodes}

Two pairs of silver chloride electrodes are used for the OBEM. We first put a pair of electrodes separated by a fixed distance within a tank filled with seawater to check the status of the electrodes. Second, we measured the electrical potential and impedance of the electrodes using a digital volt-ohm-milliammeter (VOM) (Fig. 7). Third, we sent a

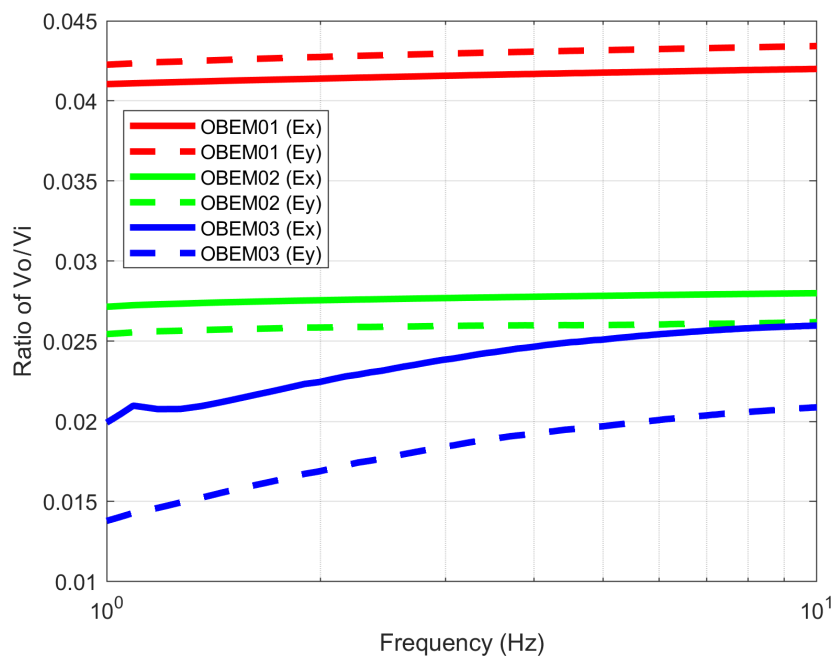

Figure 8. The responses of the electrodes with varying frequencies The response curves of $V_{\mathrm{o}} / V_{\mathrm{i}}$ are proportional to the frequency on a $\log$ scale.

swept sine signal to check the frequency responses of the electrodes, as shown in Fig. 8. Fourth, we input a DC voltage to check the electrode-induced voltages, as shown in Fig. 9. Table 3 shows the self-potential, impedance and induced voltages for each pair of electrodes. The ranges of the self-potential and impedance are $0.26-3.63 \mathrm{mV}$ and 243 $370 \Omega$, respectively. The electrical potential shows that $81-$ $167 \mathrm{mV}$ was transmitted from the $5 \mathrm{VDC}$ of the two copper electrodes.

\subsection{Evaluation of the fluxgate}

The fluxgate is mounted in the sensor ball of the OBEM. Therefore, we could only calculate the total magnetic field (TMF) (Eq. 6) measured from the three components of the fluxgate. We then compared the difference between the TMF of the OBEM and geomagnetic data of the geophysical database management system from the Central Weather $\mathrm{Bu}$ - 
Table 2. The total current consumption of the OBEMs.

\begin{tabular}{lrrr|rrr}
\hline & \multicolumn{3}{c|}{ Turn-on mode $(\mathrm{mA})$} & \multicolumn{3}{c}{ Recording mode (mA) } \\
\cline { 2 - 7 } Logger S/N & $\begin{array}{r}7.2 \mathrm{~V} \text { for } \\
\text { data logger }\end{array}$ & $\begin{array}{r}7.2 \mathrm{~V} \text { for } \\
\text { sensors }\end{array}$ & $\begin{array}{r}\text { Power } \\
\text { consumption }\end{array}$ & $\begin{array}{r}7.2 \mathrm{~V} \text { for } \\
\text { data logger }\end{array}$ & $\begin{array}{r}7.2 \mathrm{~V} \text { for } \\
\text { sensors }\end{array}$ & $\begin{array}{r}\text { Power } \\
\text { consumption }\end{array}$ \\
\hline OBEM01 & 32 & 104 & 0.98 & 31 & 105 & 0.98 \\
OBEM02 & 30 & 94 & 0.89 & 29 & 97 & 0.91 \\
OBEM03 & 29 & 103 & 0.95 & 29 & 104 & 0.96 \\
\hline
\end{tabular}

Table 3. The self-potential, impedance and induced voltage results for each pair of silver chloride electrodes.

\begin{tabular}{lrrr}
\hline & Electrical potential & Impedance & Input DC 5 V, induced voltage \\
\hline OBEM01(EX) & $0.56 \mathrm{mV}$ & $245 \Omega$ & $164 \mathrm{mV}$ \\
OBEM01(EY) & $0.26 \mathrm{mV}$ & $272 \Omega$ & $167 \mathrm{mV}$ \\
OBEM02(EX) & $3.63 \mathrm{mV}$ & $243 \Omega$ & $81 \mathrm{mV}$ \\
OBEM02(EY) & $1.93 \mathrm{mV}$ & $370 \Omega$ & $95 \mathrm{mV}$ \\
OBEM03(EX) & $2.38 \mathrm{mV}$ & $267 \Omega$ & $83 \mathrm{mV}$ \\
OBEM03(EY) & $2.1 \mathrm{mV}$ & $331 \Omega$ & $83 \mathrm{mV}$ \\
\hline
\end{tabular}

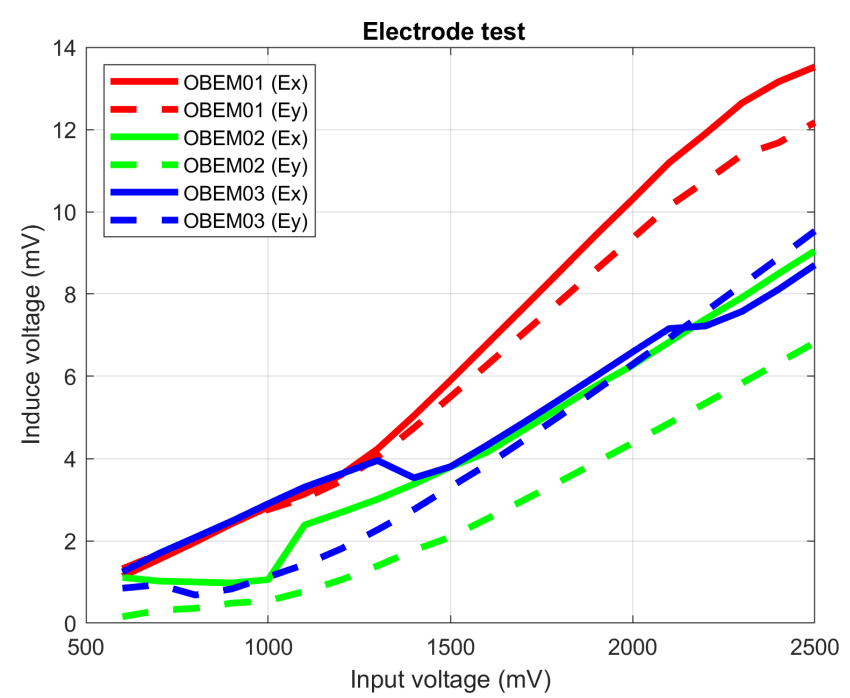

Figure 9. The responses of the electrodes with varying voltages. The input ranged from 500 to 2500 mVDC to check the induced voltage; the induced voltages are proportional to the input voltages.

reau. The TMF is calculated by

$M_{\mathrm{T}}=\sqrt{\left(M_{X}^{2}+M_{Y}^{2}+M_{Z}^{2}\right)}$,

where $M_{X}, M_{Y}$ and $M_{Z}$ are the components of the northsouth, east-west and vertical magnetic fields, respectively.

\subsection{Evaluation of the acoustic transceiver and its transducer}

We selected the large-scale Breeze Canal in New Taipei City for testing because it has few obstacles and is suitable for evaluating the functions of the $8011 \mathrm{M}$. The Breeze Canal has a length of approximately $800 \mathrm{~m}$ and is located in a straight river with a depth of $2-5 \mathrm{~m}$. The distance between the transducer and the acoustic transceiver was approximately $630 \mathrm{~m}$, and the layout for the field test is shown in Fig. 10. The testing procedure for the transducers is described below. The results are listed in Table 4.

1. Connect the tested transducer and acoustic transceiver via an underwater cable, and place the tested transducer and transceiver at an underwater depth of $1 \mathrm{~m}$.

2. Record the serial numbers of the transducers in a notebook.

3. Send the ENABLE command via the $8011 \mathrm{M}$, and then count the response beeps.

4. Send the RANGE command via the $8011 \mathrm{M}$ five times, and record the distance of each ranging.

5. Send the DISABLE command via the $8011 \mathrm{M}$, and then count the response beeps.

6. Replace the transducer, and return to step 2 to repeat the evaluation.

We then checked the acoustic transceivers after all of the transducers were successfully checked; the testing procedure for the acoustic controller is described below. The results are listed in Table 5.

1. Change the acoustic controller, and record its serial number in a notebook.

2. Send the ENABLE command via the $8011 \mathrm{M}$, and then count the response beeps. 
Table 4. Example results for the functional test of the acoustic transducer.

\begin{tabular}{lcccccccc}
\hline $\begin{array}{l}\text { Transducer } \\
\text { S/N }\end{array}$ & $\begin{array}{c}\text { Enable } \\
\text { beep } \\
\text { (times) }\end{array}$ & $\begin{array}{c}\text { Disable } \\
\text { beep } \\
\text { (times) }\end{array}$ & $\begin{array}{c}\text { First ranging } \\
\text { distance show } \\
\text { on 8011M (m) }\end{array}$ & $\begin{array}{c}\text { Second ranging } \\
\text { distance show } \\
\text { on 8011M (m) }\end{array}$ & $\begin{array}{c}\text { Third ranging } \\
\text { distance show } \\
\text { on 8011M (m) }\end{array}$ & $\begin{array}{c}\text { Fourth ranging } \\
\text { distance show } \\
\text { on 8011M (m) }\end{array}$ & $\begin{array}{c}\text { Fifth ranging } \\
\text { distance show } \\
\text { on 8011M (m) }\end{array}$ & $\begin{array}{c}\text { Judgment } \\
\text { (m) }\end{array}$ \\
\hline 35427 & 15 & 15 & 629 & 628 & 630 & 627 & 628 & Good \\
35428 & 15 & 15 & 629 & 627 & 629 & 630 & 629 & Good \\
35429 & 15 & 15 & 630 & 630 & 630 & 629 & 629 & Good \\
\hline
\end{tabular}

Table 5. Example results for the functional test of the acoustic controller.

\begin{tabular}{|c|c|c|c|c|c|c|c|c|c|c|c|}
\hline $\mathrm{S} / \mathrm{N}$ & $\begin{array}{r}\text { Enable } \\
\text { beep } \\
\text { (times) }\end{array}$ & $\begin{array}{l}\text { First ranging } \\
\text { distance show } \\
\text { on } 8011 \mathrm{M}(\mathrm{m})\end{array}$ & $\begin{array}{l}\text { Second ranging } \\
\text { distance show } \\
\text { on } 8011 \mathrm{M}(\mathrm{m})\end{array}$ & $\begin{array}{l}\text { Third ranging } \\
\text { distance show } \\
\text { on } 8011 \mathrm{M}(\mathrm{m})\end{array}$ & $\begin{array}{l}\text { Fourth ranging } \\
\text { distance show } \\
\text { on } 8011 \mathrm{M}(\mathrm{m})\end{array}$ & $\begin{array}{l}\text { Fifth ranging } \\
\text { distance show } \\
\text { on } 8011 \mathrm{M}(\mathrm{m})\end{array}$ & $\begin{array}{r}\text { RELEASE1 } \\
\text { beep times/ } \\
\text { volt }\end{array}$ & $\begin{array}{r}\text { OPTION1 } \\
\text { beep } \\
\text { (times) }\end{array}$ & $\begin{array}{r}\text { RELEASE2 } \\
\text { beep times/ } \\
\text { volt }\end{array}$ & $\begin{array}{r}\text { OPTION1 } \\
\text { beep } \\
\text { (times) }\end{array}$ & $\begin{array}{r}\text { DISABLE } \\
\text { beep } \\
\text { (times) }\end{array}$ \\
\hline 50854 & 15 & 628 & 629 & 630 & 630 & 630 & $15 / 12.77 \mathrm{~V}$ & 15 & $15 / 12.77 \mathrm{~V}$ & 15 & 15 \\
\hline 50784 & 7 & 629 & 630 & 630 & 630 & 630 & $7 / 12.77 \mathrm{~V}$ & 7 & $7 / 12.77 \mathrm{~V}$ & 7 & 7 \\
\hline 50783 & 15 & 628 & 628 & 628 & 629 & 631 & $15 / 12.77 \mathrm{~V}$ & 15 & $15 / 12.77 \mathrm{~V}$ & 15 & 15 \\
\hline
\end{tabular}

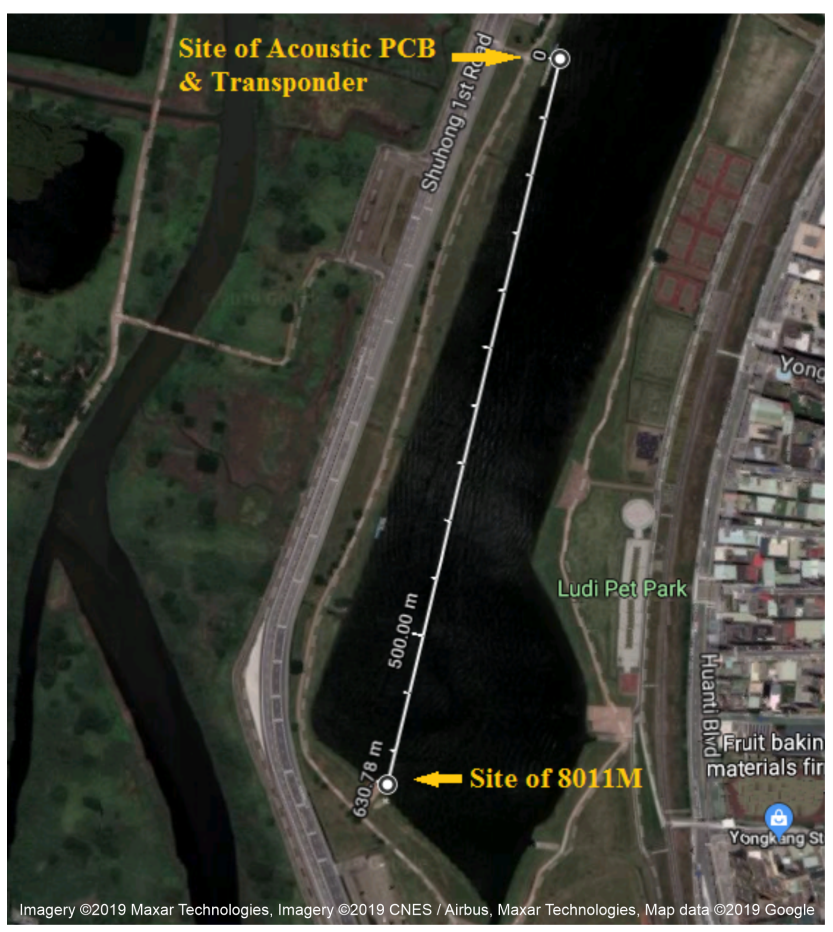

Figure 10. A map of the field test to evaluate the acoustic transducer, acoustic controller and $8011 \mathrm{M}$ (modified from Google Maps, https://www.google.com.tw/maps/@25.0902745, $121.4516598,1296 \mathrm{~m} / \mathrm{data}=! 3 \mathrm{~m} 416$, last access: 19 August 2019).

3. Send the RANGE command via the $8011 \mathrm{M}$ five times, and record the distance of each ranging.

4. Send the RELEASE1 command via the 8011M, and then count the response beeps. Check the voltage between Pin 1 and Pin 2 of JP2 using a VOM. It should be greater than $12.0 \mathrm{VDC}$.

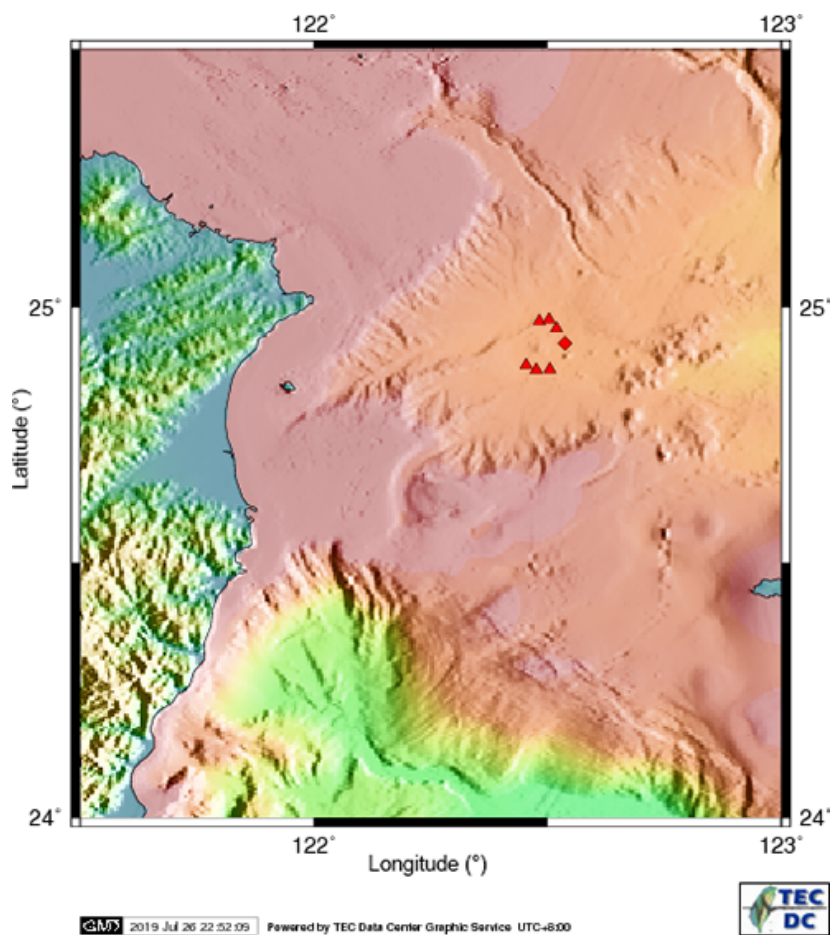

Figure 11. A location map showing the Yardbird-BBs and OBEM with triangle and diamond symbols, respectively.

5. Send the "OPTION1" command via the $8011 \mathrm{M}$, and then count the response beeps. Check the voltage between Pin 1 and Pin 2 of JP2 using a VOM. It should be $0 \mathrm{VDC}$

6. Send the RELEASE2 command via the $8011 \mathrm{M}$, and then count the response beeps. Check the voltage between Pin 3 and Pin 4 of JP2 using a VOM. It should be greater than $12.0 \mathrm{VDC}$. 


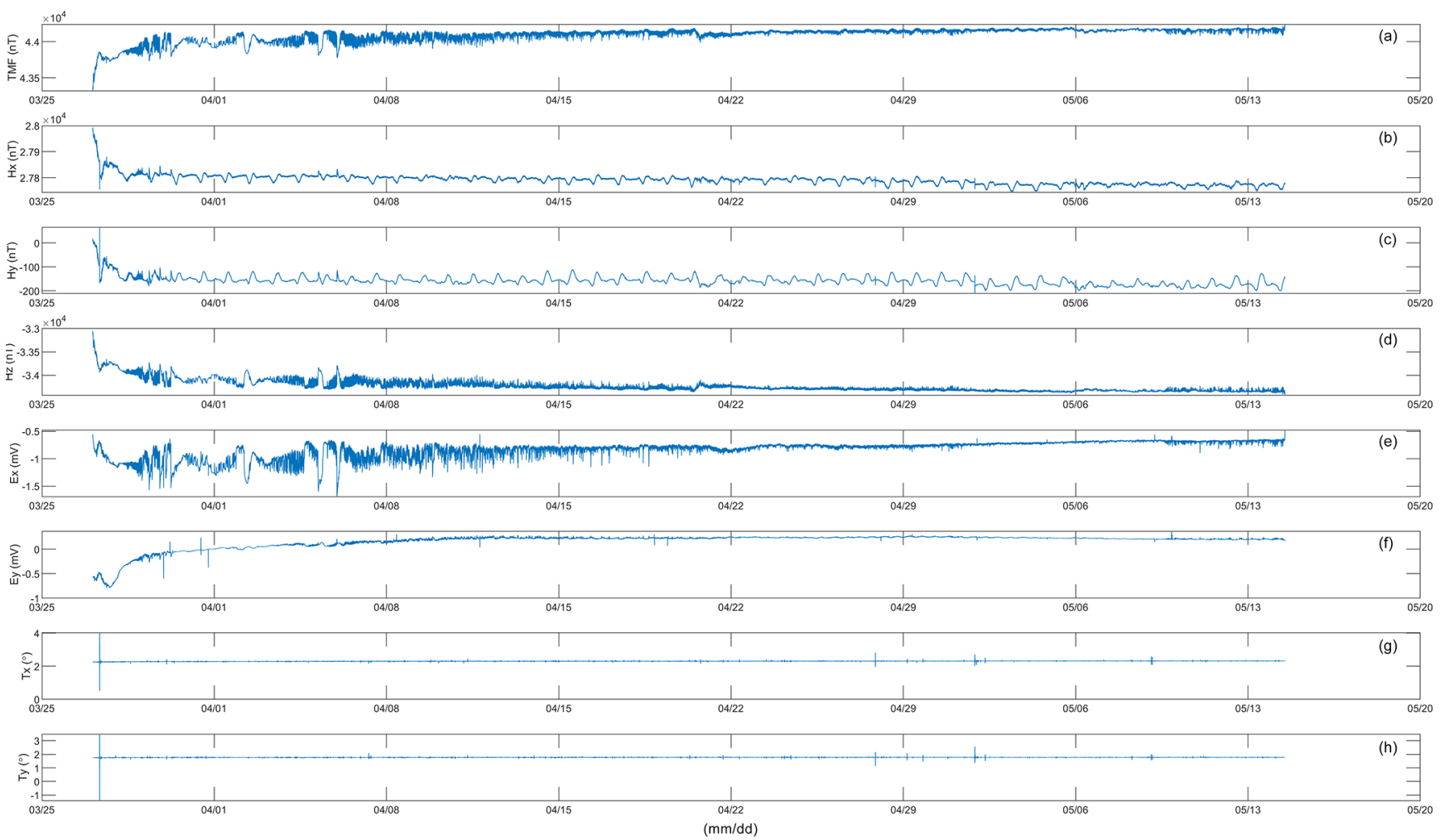

Figure 12. The OBEM01 time series data. The panels from top to bottom in the figure show the four magnetic fields (a-d: TMF, HX, HY and HZ), the two electric fields (e, f: EX and EY) and the two inclinations (g, h: TX and TY).

7. Send the OPTION1 command via the $8011 \mathrm{M}$, and then count the response beeps. Check the voltage between Pin 3 and Pin4 of JP2 using a VOM. It should be 0 VDC.

8. Send the DISABLE command via the $8011 \mathrm{M}$, and then count the response beeps.

9. Send the RANGE command via the $8011 \mathrm{M}$; there should be no response from the transceiver.

10. Return to step 1 to repeat the evaluation.

A mercury switch is mounted on the transceiver which when turned off responds with 15 beeps and when turned on responds with seven beeps.

\section{The preliminary result of the OBEM offshore Taiwan}

We deployed six Yardbird-BBs and one OBEM near a small submarine volcano area in the OT offshore NE Taiwan (Fig. 11) on 26 March 2018 for a submarine observation to evaluate all the OBEM units. All the equipment was successfully recovered after 1 month of deployment. Figure 12 shows the time series of data of OBEM01. The TMF calculated from the three components of the magnetic field varied in the range of $44100-44150 \mathrm{nT}$, which corresponded to the geomagnetic field measured by proton magnetometers in
Taiwan. The two horizontal magnetic fields contained significant daily variations. Furthermore, the vibrations of the inclinations were significantly affected by two earthquakes on 27 April 2018 (at 12:41 and 12:47 UTC) consistent with seismic signals of the Yardbird-BBs (Fig. 13). The average magnetic fields of HX, HY, HZ and TMF $2 \mathrm{~s}$ prior to the earthquakes (12:41 UTC) were 12900, 34300, 24600 and $44137 \mathrm{nT}$, respectively, the average potential fields of EX and $\mathrm{EY}$ were -0.79 and $-0.149 \mathrm{mV}$, respectively, and the inclinations of TX and TY were -2.65 and $1.21^{\circ}$, respectively. These were the averages of the background without earthquakes.

We subtracted the background averages of the magnetic fields and the inclinations to compare the differential during the 12:41 UTC event as shown in Fig. 14. The peak ground motion velocity (PGV) was $2.63 \mathrm{~cm} \mathrm{~s}^{-1}$ on the SH1 corresponding to inclinations of 0.4 and $0.6^{\circ}$ for TX and TY with a $100 \mathrm{nT}$ disturbance of HY. There was an insignificant amount of variation in the electric fields. The result shows that the earthquake significantly affected the HY component, whereas HX and HZ components also slightly affected by the earthquake. It could be related to the orientations of the magnetic sensor and the earthquake. 

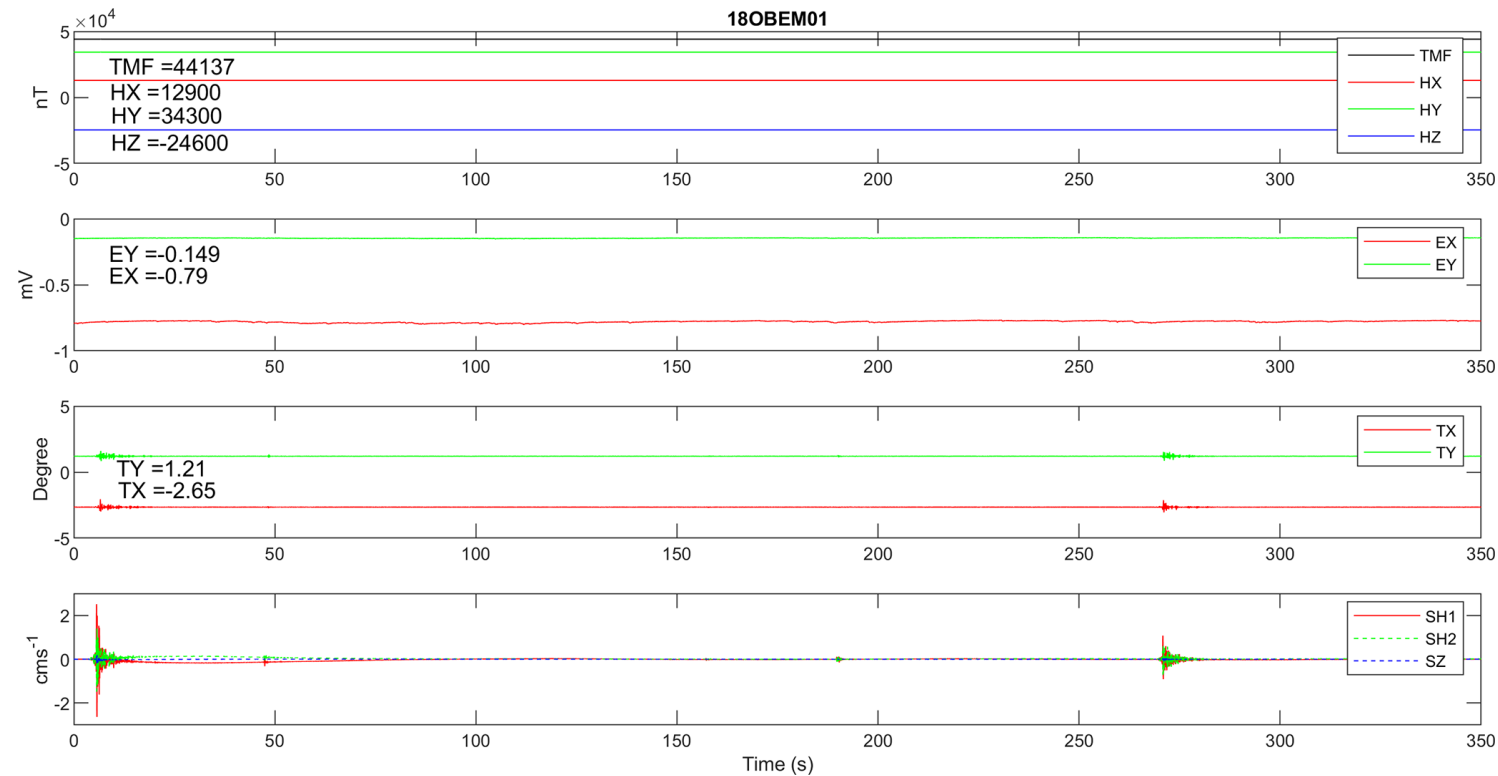

Figure 13. Comparison of the OBEM01 and 1802OBS time series data during the two earthquakes. The two earthquakes affected the inclinations. The first and secondary earthquakes occurred at 12:41 and 12:47 UTC, respectively, on 27 April 2018. SH1 and SH2: two horizontal components of the seismic signal; SZ: vertical component of the seismic signal.
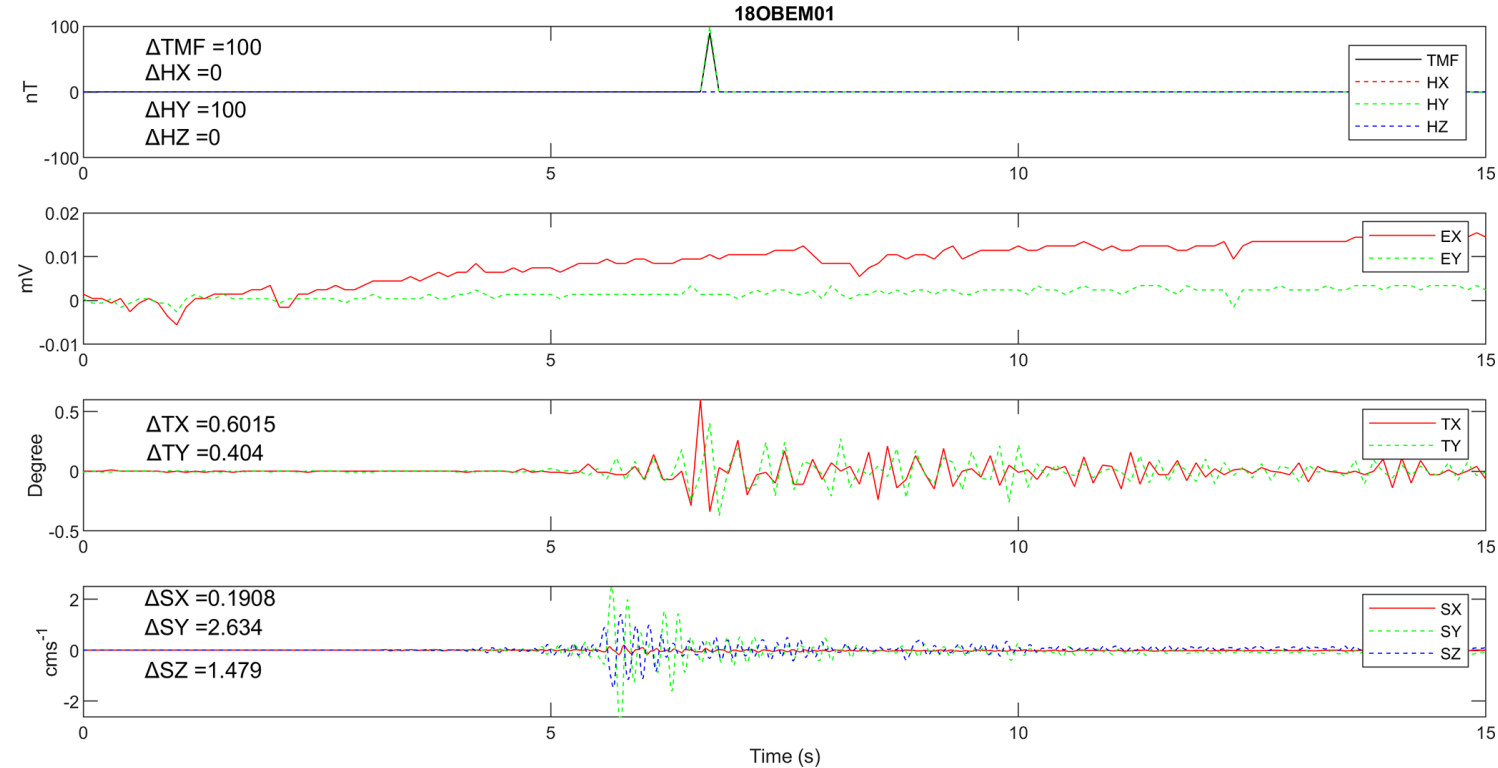

Figure 14. The variations in PGV, TMF, HY, TX and TY during the first earthquake. The PGV of $2.63 \mathrm{~cm} \mathrm{~s}^{-1}$ affected the inclinations by 0.601 and $0.404^{\circ}$ for TX and TY, respectively, and the HY magnetic field had a peak of $100 \mathrm{nT}$. SH1 and SH2: two horizontal components of the seismic signal; SZ: vertical component of the seismic signal.

\section{Conclusions}

A long-period OBEM acquisition platform to measure magnetic and electrical fields on the seafloor was successfully constructed and evaluated by the OBS R\&D team for deployment offshore Taiwan. The power consumption of the OBEM is less than $1 \mathrm{~W}$, which means that the lifetime could be ex- tended up to $300 \mathrm{~d}$ with the installation of 108 lithium batteries. We deployed and recovered the OBEM at an underwater depth of $1400 \mathrm{~m}$ to acquire the first marine magnetotelluric data offshore NE Taiwan.

Six Yardbird-BBs and one OBEM were deployed near a small submarine volcano area offshore NE Taiwan. The TMF calculated from the three magnetic field components varied 
in the range of $44100-44150 \mathrm{nT}$, which corresponded to the proton magnetometer measurements of the geomagnetic field in Taiwan. The two horizontal magnetic fields displayed significant daily variations, and the vibrations of the inclinations were significantly affected by the two earthquakes that occurred during the observations. There was an insignificant amount of variation in the electric fields.

Localized microearthquakes affected the disturbances of the magnetic field and inclinations in this study. Therefore, to improve the efficacy of marine geophysical explorations, a platform for multiple underwater measurements is required including an ocean bottom flowmeter, thermometer and absolute pressure gage. We will focus on such developments, in which the evaluated results show that the data logger, flush and radio beacons, EMI filter, and an integrated junction board must be improved in relation to noise levels, cost and convenient maintenance issues in the future.

Data availability. The data used in the paper can be accessed by contacting the corresponding author.

Author contributions. CRL and CWC wrote the paper with contributions from all authors. KYH primarily provided results on testing and characterizing OBEM performance. The OBEMs presented here were developed at the Taiwan Ocean Research Institute led by YHH under a contract from the National Ocean Taiwan University, Academia Sinica, the National Applied Research Laboratories and the National Taiwan University. PCC, HKC and JPJ designed, constructed, built, assembled and tested infrastructure at the Taiwan Ocean Research Institute used to characterize and document OBEM for this paper. KHC and FSL completed preliminary tests of the OBEM manufacturing process. SL and BYK primarily completed the literature review on the OBEM.

Competing interests. The authors declare that they have no conflict of interest.

Acknowledgements. We greatly appreciate the crews of R/V OR2 for the field experiments. We also thank 4 years of the TaiwanGerman cooperative projects on gas hydrate of NEPII for supporting the funds of the instrument deployment of the OBEMs. We would like to thank the TEC Data Center for proving graphical services. We are also grateful for valuable comments and suggestions of the reviewers.

Financial support. This research has been supported by the MOST, TAIWAN (grant nos. 101-3113-P-002-013, 102-3113-P-002-005, 103-3113-M-002-004, 104-3113-M-002-004, 105-2116-M-019001, 106-2116-M-001-008, 106-2116-M-019-003, 107-2116-M019-006, 108-2116-M-001-012 and 108-2116-M-019-006).
Review statement. This paper was edited by Valery Korepanov and reviewed by Kai Chen and Denghai Bai.

\section{References}

Bertrand, E., Unsworth, M., Chiang, C. W., Chen, C. S., Chen, C. C., Wu, F., Turkoglu, E., Hsu, H. L., and Hill, G.: Magnetotelluric evidence for thick-skinned tectonics in central Taiwan, Geology, 37, 711-714, 2009.

Bertrand, E. A., Unsworth, M. J., Chiang, C. W., Chen, C. S., Chen, C. C., Wu, F. T., Turkoglu, E., Hsu, H. L., and Hill, G. J.: Magnetotelluric imaging beneath the Taiwan orogen: An arc-continent collision, J. Geophys. Res.-Sol. Ea., 117, B01402, https://doi.org/10.1029/2011JB008688, 2012.

Chiang, C. W., Unsworth, M. J., Chen, C. S., Chen, C. C., Lin, A. T. S., and Hsu, H. L.: Fault zone resistivity structure and monitoring at the Taiwan Chelungpu Drilling Project (TCDP), Terr. Atmos. Ocean Sci., 19, 473-479, 2008.

Chiang, C. W., Chen, C. C., Unsworth, M., Bertrand, E., Chen, C. S., Thong, D. K., and Hsu, H. L.: The deep electrical structure of southern Taiwan and its Tectonic Implications, Terr. Atmos. Ocean Sci., 21, 879-895, 2010.

Chiang, C. W., Chen, C. C., Unsworth, M., Bertrand, E., Chen, C. S., Kieu, T. D., and Hsu, H. L.: Corrigendum to "The deep electrical structure of southern Taiwan and its tectonic implications", Terr. Atmos. Ocean Sci., 22, 371-371, 2011.

Chiang, C. W., Hsu, H. L., and Chen, C. C.: An investigation of the 3D electrical resistivity structure in the Chingshui geothermal area, NE Taiwan, Terr. Atmos. Ocean Sci., 26, 269-281, 2015.

Ellis, M., Evans, R. L., Hutchinson, D., Hart, P., Gardner, J., and Hagen, R.: Electromagnetic surveying of seafloor mounds in the northern Gulf of Mexico, Mar. Pet. Geol., 25, 960-968, 2008.

Evans, R. L., Hirth, G., Baba, K., Forsyth, D., Chave, A., and Mackie, R.: Geophysical evidence from the MELT area for compositional controls on oceanic plates, Nature, 437, 249-252, 2005.

Kasaya, T. and Goto, T.: A small ocean bottom electromagnetometer and ocean bottom electrometer system with an arm-folding mechanism, Explor. Geophys., 40, 41-48, 2009.

Key, K.: Marine Electromagnetic Studies of Seafloor Resources and Tectonics, Surv. Geophys., 33, 135-167, 2012.

Kuo, B. Y., Wang, C. C., Lin, S. C., Lin, C. R., Chen, P. C., Jang, J. P., and Chang, H. K.: Shear-wave splitting at the edge of the Ryukyu subduction zone, Earth Planet. Sc. Lett., 355, 262-270, 2012.

Kuo, B. Y., Webb, S. C., Lin, C. R., Liang, W. T., and Hsiao, N. C.: Removing infragravity-wave-induced noise from Ocean-Bottom Seismographs (OBS) data deployed offshore of Taiwan, B. Seismol. Soc. Am., 104, 1674-1684, 2014.

Kuo, B. Y., Crawford, W. C., Webb, S. C., Lin, C. R., Yu, T. C., and Chen, L. W.: Faulting and hydration of the upper crust of the SW Okinawa Trough during continental rifting: Evidence from seafloor compliance inversion, Geophys. Res. Lett., 42, 48094815, 2015.

Utada, H.: Electromagnetic exploration of the oceanic mantle, P. Jpn. Acad. B-Phys., 91, 203-222, 2015. 